\title{
Food insecurity among refugee families in East London: results of a pilot assessment
}

\author{
Daniel W Sellen ${ }^{1,2, *}$, Alison E Tedstone ${ }^{2}$ and Jacqueline Frize ${ }^{2}$ \\ 'Department of Anthropology, Emory University, Atlanta, GA 30322, USA: ${ }^{2}$ Public Health Nutrition Unit, London \\ School of Hygiene and Tropical Medicine, London, UK
}

Submitted 17 October 2001: Accepted 1 March 2002

\begin{abstract}
Objective: To identify child hunger and examine its association with family factors, receipt of benefits, housing conditions and social support among recently arrived refugee families with young children.

Design: Structured and semi-structured questionnaire administered to a servicebased, purposive sample of caregivers.

Setting: East London, United Kingdom.

Subjects: Thirty households with children $<5$ years old, resident in the UK for $<2$ years.

Results: All households sampled were food-insecure, and 60\% of index children were experiencing hunger as defined on the Radimer/Cornell scale. Child hunger was significantly associated with recent arrival, marginally significantly associated with receipt of fewer benefits and younger parenthood, and not associated with maternal education or self-efficacy score, household size or composition, or measures of social support.

Conclusions: A community-based, participatory approach for rapid assessment of the prevalence, extent and causes of child hunger among newly arrived asylum seekers recently arrived in Britain is feasible, and preliminary results suggest a programmatic need for a broader, population-based assessment of food insecurity in this rapidly growing population group.
\end{abstract}

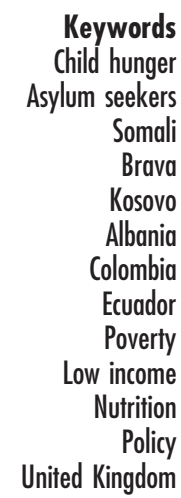

Refugees constitute the most economically deprived and socially excluded UK population segment ${ }^{1,2}$, and suffer poor nutritional and health outcomes ${ }^{3-5}$ linked to poverty and social exclusion rather than to experience before arrival $^{1,6,7}$. London is home to $85 \%$ of refugees entering the UK since $1985^{\circ}$, and $88 \%$ of school-aged refugee children 9 . These approximately 250000 resettled refugees increase the demand for health, education, legal, housing and other social services ${ }^{10,11}$. Recent research reveals gaps in service provision to refugees that include appropriate language advocacy, insufficient provision of information about health care rights and limited awareness of refugee issues among health professionals ${ }^{12,13}$. Statutory and voluntary providers express concerns that limited access to cash and transport, irregular lifestyles, temporary accommodation with inadequate cooking facilities and social isolation of mothers with young children adversely affect the nutritional well-being of refugee families ${ }^{14}$. To date, no assessment has been carried out to evaluate these concerns or develop nutrition interventions among Britain's diverse, sizeable and growing refugee communities.

Household food insecurity occurs 'whenever the availability of nutritionally adequate and safe foods or the ability to acquire acceptable foods in socially acceptable ways is limited or uncertain' and is manifest as 'a managed process with a general sequence as the problem worsens ${ }^{15}$. Household food insecurity is experienced first, followed by compromises in the quality and quantity of food eaten by adults. Child hunger, characterised by decreases in the quantity of food eaten by children, is the last stage, indicating severe household food insufficiency. We report here results of a recent partnership between The Children's Society East London Project Homeless Families Support Team, the London School of Hygiene and Tropical Medicine Public Health Nutrition Unit and Emory University to assess food insecurity among refugee families with pre-school-aged children living in or near the London Borough of Newham, which is home to approximately half of the child refugee population of East London ${ }^{9,16}$. Questions addressed were the following. (1) Do asylum seekers with young children experience food insecurity? (2) Do any welfare benefits received protect against child hunger? (3) Does social support from families protect against child hunger? 


\section{Methods}

The study was approved by the East London \& City Health Authority, the London School of Hygiene and Tropical Medicine and Emory University, and was carried out over 7 months (March-October 2000). All informants and survey participants gave written informed consent to participate.

\section{Formative research}

To assess perceived nutrition needs of refugees and inform design of an assessment tool, we conducted six unstructured interviews with key informants and facilitated two focus group discussions with community leaders, case workers and project co-ordinators working directly with refugees. Consensus emerged that a detailed questionnaire could serve as a reliable tool for the rapid assessment of threats to young child nutrition, if developed and tested using a community participatory approach and administered to principal caregivers in a representative cross-section of refugee households ${ }^{17}$. To identify target communities for study, we reviewed records from the New Entrants Health Screening Service of the London Borough of Newham.

\section{Development of survey instrument and fieldworker training}

We used an ethnographic approach to collect specific, contextual information needed to develop a culturally and locally appropriate prototype instrument for nutrition assessment among refugees in East London. First, we identified, through various refugee outreach organisations, five key informants per target community ( $n=15$; selection criteria: refugee status, motherhood, $<2$ years' residence in the UK, competence in English). Second, we incorporated into a draft questionnaire crossvalidated information about foods typically consumed, family arrangements, living conditions, social and economic activity, and suggestions about factors influencing household food security and pre-school child diets elicited from 12 of these key informants by semi-structured, depth interviews conducted in English. Third, we pre-tested this prototype survey instrument with the fifth key informant from each study community and obtained feedback by interview.

We then trained a team of three fieldworkers recruited from within each target community in the objectives of the project, basic nutrition knowledge, interviewing techniques, and procedures for obtaining consent, maintaining confidentiality and quality assurance. All were fluent in their native language and English, resided locally, were mothers and were familiar with the experience of refugees in the UK. This team modified the format, layout and content of pre-coded response sets of the prototype to improve comprehension, relevance and cultural acceptability to the target communities and ease of completion by interviewers. Each fieldworker translated the modified version into her own language and tested it on a newly arrived refugee family during a practice interview observed by a lead investigator. Revised foreign-language versions were translated back into English by a third party and amendments made to resolve any remaining inconsistencies. The instrument yielded over 400 items of information, of which the following were retained for this analysis.

- Sociodemographic. All family members: age, sex, ethnic and religious self-identification, and immigration status; caregivers: marital status, education, reproductive and residential history.

- Household. Employment, income and welfare benefits received by household members; type of housing and rental arrangements; cooking, storage and sleeping facilities.

- Social support. Arrangements for childcare and feeding; frequency and type of assistance from family or voluntary and statutory bodies.

- Food insecurity. Assessed for household, caregiver and index child using the 10-item version of the Radimer/ Cornell Hunger Scale ${ }^{15,18,19}$ with minor changes in wording (Table 1). Households were categorised as food-secure if responses to all questions were negative. Households were categorised as food-insecure only at the household level if at least one response to items 14 , but not 5-10, was positive; as having adult food insecurity if at least one response to items 5-8 was positive; and as having child hunger if at least one response to items 9 and 10 was positive.

\section{Recruitment}

We aimed to interview a representative sample of 10 families with a pre-school-aged index child from each target community $(n=3)$ identified through formative research. Selection criteria were: asylum-seeking status of household head; UK residence not exceeding 24 months prior to interview; presence of a child under 5 years; current residence in or near Newham. The Children's Society provided an initial list of potential participant families in compliance with data protection requirements. Fieldworkers contacted principal caregivers by telephone or home visit to arrange interviews. Fieldworkers developed an appropriate snowballing strategy for subsequent recruitment (i.e. word-of-mouth referral, telephone invitation, networking at playgroups, etc.) and translated interviews conducted in each study community language into English. Respondents received $\$ 10$ participation incentive. To ensure quality data collection the lead investigators randomly observed survey interviews and met regularly with the field team to review progress.

\section{Data management}

We double-entered information from completed 
Table 1 Radimer/Cornell hunger and food insecurity items

\begin{tabular}{|c|c|c|c|c|c|c|}
\hline \multirow[b]{2}{*}{ Level } & \multirow[b]{2}{*}{ Component } & \multirow[b]{2}{*}{ Statements for caregiver evaluation } & \multicolumn{4}{|c|}{ Classification of food insecurity* } \\
\hline & & & $\begin{array}{l}\text { Food } \\
\text { secure }\end{array}$ & $\begin{array}{l}\text { Household } \\
\text { insecure }\end{array}$ & $\begin{array}{l}\text { Individual } \\
\text { insecure }\end{array}$ & $\begin{array}{r}\text { Child } \\
\text { hunger }\end{array}$ \\
\hline \multirow[t]{4}{*}{ Household } & Food anxiety & $\begin{array}{l}\text { 1. I worry whether my food will run out before } \\
\text { I get money to buy more. }\end{array}$ & - & + & $\mathrm{n} / \mathrm{a}$ & $\mathrm{n} / \mathrm{a}$ \\
\hline & Qualitative & $\begin{array}{l}\text { 2. We eat the same thing for several days in a } \\
\text { row because we only have a few different kinds of } \\
\text { food on hand and do not have money to buy more. }\end{array}$ & - & + & $\mathrm{n} / \mathrm{a}$ & $\mathrm{n} / \mathrm{a}$ \\
\hline & Quantitative & $\begin{array}{l}\text { 3. The food that I bought just did not last, and I did not } \\
\text { have money to get more. }\end{array}$ & - & + & $\mathrm{n} / \mathrm{a}$ & $\mathrm{n} / \mathrm{a}$ \\
\hline & & $\begin{array}{l}\text { 4. I ran out of the foods that I needed to put together } \\
\text { a meal and I did not have money to get more food. }\end{array}$ & - & + & $\mathrm{n} / \mathrm{a}$ & $\mathrm{n} / \mathrm{a}$ \\
\hline \multirow[t]{3}{*}{ Adult } & Qualitative & $\begin{array}{l}\text { 5. I am often hungry, but I do not eat because I cannot } \\
\text { afford enough food. }\end{array}$ & - & - & + & $\mathrm{n} / \mathrm{a}$ \\
\hline & & $\begin{array}{l}\text { 6. I eat less than I think I should because I do not have } \\
\text { enough money for food. }\end{array}$ & - & - & + & $\mathrm{n} / \mathrm{a}$ \\
\hline & Quantitative & 7. I cannot afford to eat properly. & - & - & + & $\mathrm{n} / \mathrm{a}$ \\
\hline \multirow[t]{3}{*}{ Child } & Qualitative & $\begin{array}{l}\text { 8. I cannot give my child(ren) a balanced meal because } \\
\text { I cannot afford that. }\end{array}$ & - & - & + & $\mathrm{n} / \mathrm{a}$ \\
\hline & Quantitative & $\begin{array}{l}\text { 9. My child(ren) is/are not eating enough because I just } \\
\text { cannot afford enough food. }\end{array}$ & - & - & - & + \\
\hline & & $\begin{array}{l}\text { 10. I know my child(ren) is/are hungry sometimes, but I } \\
\text { just cannot afford more food. }\end{array}$ & - & - & - & + \\
\hline
\end{tabular}

*Based on positive ('often true' or 'sometimes true') or negative ('never true') evaluative response.

questionnaires into Epi-Info ${ }^{20}$, grouped households on indicators of food insecurity and used $\operatorname{SPSS}^{21}$ to test for association with other measures, allowing 10\% Type 1 error for inferences.

\section{Results}

\section{Recruitment}

We identified the Bravanese (Somali), Kosovan (Albanian) and South American (Colombian or Ecuadorian) as the largest and most rapidly growing refugee communities in Newham during 2000. We contacted 34 mothers to achieve the target sample of 10 families per group (all refusals were Colombian). Most interviews were conducted in the family home $(87 \%)$ or at The Children's Society offices.

\section{Sample characteristics}

A majority of families were awaiting a Home Office decision on an Asylum Claim ( $n=12$, 'Point of Entry'; $n=6$, 'In-country') filed within the previous 24 months (11.5 \pm 7.8 months) or were appealing against a recent negative decision (Table 2). A minority had Exceptional (3\%) or Indefinite (10\%) Leave to Remain. Families had been resident in the UK for an average of $13.0 \pm 6.8$ (range: 0-25) months. A majority had settled first in London (53\% in Newham, 43\% in another London borough; one family lived first in Hastings). Only five (17\%) still occupied their first UK home. Mean age at arrival was $23.2 \pm 13.0$ (range: 3-46) months among index children born abroad (77\%).

All respondents were natural mothers of the index child and self-identified as principal caregivers. Few spoke
English (10\%), and none claimed fluency. Although the majority were married, one-third were lone parents. Fathers were not resident in $43 \%$ of households. Only one household had an income earner (a partner who worked as a cleaner and who also received a job-seekers allowance).

A majority (83\%) of families were housed in properties paid for by the council, about half of which were owned by private landlords. The money paid by the council covered the full cost of the rent for only a quarter of these families. Most families (83\%) were receiving some benefits at the time of interview, and all claimed Family Credit. Two families had never received any benefits. Benefits were suspended for three families recently refused asylum. No families received free vitamins and only a single family received Child Allowance.

Index children were cared for only rarely by other relatives and never by paid childminders or at a nursery or day care centre. A majority of mothers lived near kin (53\%), friends (33\%) or in-laws (3\%) from the same ethnic community and knew somebody in the UK before arrival (69\%). Only two mothers reported receiving no help from friends and family. Fewer mothers felt that they themselves were fitting into life in the UK (27\%) than were their families (37\%). The families maintained links with their community mainly through celebrating community holidays (77\%) and also by reading community papers (40\%), attending community gatherings (37\%) and listening to community radio (33\%).

\section{Food insecurity}

All households were food-insecure, and child hunger was 
Table 2 Selected sample characteristics ( $n=30$ families)

\begin{tabular}{|c|c|c|}
\hline & $n(\%)^{*}$ & $\begin{array}{l}\text { Mean } \pm S D \\
\quad \text { (range) }\end{array}$ \\
\hline \multicolumn{3}{|l|}{ Immigration status } \\
\hline Asylum Claim pending $\dagger$ & $18(60)$ & \\
\hline Appealing & $8(27)$ & \\
\hline Granted Leave to Remain & $4(13)$ & \\
\hline \multicolumn{3}{|l|}{ Home moves since arrival } \\
\hline None & $5(17)$ & \\
\hline One & $17(57)$ & \\
\hline Two or more & $8(27)$ & \\
\hline Number of adults & - & $2.0 \pm 1.1(1-5)$ \\
\hline Number of children, $5-18$ years & - & $0.8 \pm 1.1(0-4)$ \\
\hline Number of children, $<5$ years & - & $1.5 \pm 0.6(1-3)$ \\
\hline Index child's age (months) & & $30.3 \pm 16.3(1-60)$ \\
\hline$<12$ & $3(10)$ & \\
\hline $12-35$ & $13(43)$ & \\
\hline $36-60$ & $14(46)$ & \\
\hline Male & $19(63)$ & \\
\hline Female & $11(37)$ & \\
\hline Mother's age (years) & & $26.0 \pm 5.5(19-43)$ \\
\hline$<20$ & $4(13)$ & \\
\hline $21-30$ & $22(73)$ & \\
\hline$>30$ & $4(13)$ & \\
\hline \multicolumn{3}{|l|}{ Marital status } \\
\hline Married & $24(80)$ & \\
\hline Single & $4(13)$ & \\
\hline Cohabiting & $1(3)$ & \\
\hline Separated & $1(3)$ & \\
\hline \multicolumn{3}{|l|}{ Schooling (years) } \\
\hline None & $6(20)$ & \\
\hline$<6$ & $3(10)$ & \\
\hline $6-12$ & $18(60)$ & \\
\hline$>12$ & $3(10)$ & \\
\hline \multicolumn{3}{|l|}{ Religion } \\
\hline Muslim & $16(53)$ & \\
\hline Christian & $9(30)$ & \\
\hline None & $5(17)$ & \\
\hline \multicolumn{3}{|l|}{ Principal caregiver } \\
\hline Mother only & $24(80)$ & \\
\hline Mother and father only & $5(17)$ & \\
\hline Mother and other relative(s), not father & $1(3)$ & \\
\hline \multicolumn{3}{|l|}{ Household composition } \\
\hline Lone parent & $11(37)$ & \\
\hline Nuclear family & $10(33)$ & \\
\hline Extended family & $8(27)$ & \\
\hline Shared with non-kin & $1(3)$ & \\
\hline
\end{tabular}

SD - standard deviation.

${ }^{*}$ Percentage figures may not sum to $100 \%$ due to rounding.

$\dagger n=12$, 'Point of Entry'; $n=6$, 'In-country'.

indicated in almost two-thirds (Table 3). Nearly two-thirds of respondents always worried that their food would run out, and no respondents reported never having that worry. The level of food insecurity varied among ethnic groups, with South Americans at highest risk for child hunger $\left(\chi_{3,1}^{2}=5.035, P=0.025\right)$.

To examine factors associated with food insecurity, families were divided into two groups, those with and without child hunger, and compared on a number of factors hypothesised to contribute to, correlate with or ameliorate child hunger (Table 4).

\section{Length of residence in the UK}

Families experiencing child hunger had arrived in the UK, migrated to London, and filed their application for asylum
Table 3 Prevalence of food insecurity among asylum seekers with young children

\begin{tabular}{lrc}
\hline & $n$ & $\%$ \\
\hline Food secure & 0 & 0 \\
Food insecure & 30 & 100 \\
Household food insecure & 2 & 7 \\
Adult food insecure & 10 & 33 \\
Child hunger & 18 & 60 \\
\hline Ethnic group & & \% Child hunger \\
\hline Colombian/Ecuadorean & 9 & 90 \\
Kosovo Albanian & 5 & 50 \\
Bravanese Somali & 4 & 40 \\
\hline
\end{tabular}


Table 4 Bivariate associations between child hunger and household and caregiver factors

\begin{tabular}{|c|c|c|c|c|}
\hline \multirow[b]{2}{*}{ Variable (units) } & \multirow[b]{2}{*}{$n$} & \multicolumn{3}{|c|}{ Child hunger group } \\
\hline & & With (18) & Without (12) & $P^{\star}$ \\
\hline Length of time since arrival in UK (months) & 30 & $10.9 \pm 6.8$ & $16.0 \pm 5.7$ & 0.021 \\
\hline Time since filing application for asylum (months) & 30 & $9.1 \pm 8.2$ & $15.1 \pm 6.0$ & 0.046 \\
\hline Time resident in a London borough (months) & 30 & $10.9 \pm 14.3$ & $23.7 \pm 2.6 .0$ & 0.048 \\
\hline Principal caregiver's age (years) & 30 & $24.8 \pm 3.8$ & $27.7 \pm 7.0$ & 0.086 \\
\hline Principal caregiver's education (years) & 30 & $7.2 \pm 4.4$ & $7.8 \pm 5.6$ & 0.469 \\
\hline Principal caregiver's self-efficacy score (1-4 scale) & 30 & $2.5 \pm 0.6$ & $2.5 \pm 0.5$ & 0.867 \\
\hline Number of children in household & 30 & $2.2 \pm 1.3$ & $2.5 \pm 1.5$ & 0.262 \\
\hline Number of adults in household & 30 & $2.0 \pm 1.0$ & $2.0 \pm 1.2$ & 0.500 \\
\hline Number of caregivers & 30 & $1.2 \pm 0.4$ & $1.3 \pm 0.5$ & 0.296 \\
\hline Lone caregiver & 24 & $62.5 \%$ & $37.5 \%$ & \\
\hline Other caregivers & 6 & $50.0 \%$ & $50.0 \%$ & 0.455 \\
\hline \multicolumn{5}{|l|}{ Presence of father } \\
\hline Absent & 13 & $53.8 \%$ & $46.2 \%$ & \\
\hline Present & 17 & $64.7 \%$ & $35.3 \%$ & 0.410 \\
\hline \multicolumn{5}{|l|}{ Friend/family already in UK } \\
\hline Yes & 20 & $44.4 \%$ & $35.0 \%$ & \\
\hline No & 9 & $55.6 \%$ & $65.0 \%$ & 0.466 \\
\hline \multicolumn{5}{|l|}{ Friend/family already in UK have helped family } \\
\hline Yes & 18 & $50.0 \%$ & $33.3 \%$ & \\
\hline No & 2 & $50.0 \%$ & $66.7 \%$ & 0.589 \\
\hline \multicolumn{5}{|l|}{ Family/friends lend/borrow money and or goods } \\
\hline Yes & 21 & $61.9 \%$ & $38.1 \%$ & \\
\hline No & 8 & $50.0 \%$ & $50.0 \%$ & 0.432 \\
\hline \multicolumn{5}{|l|}{ Benefits } \\
\hline Some benefits received & 25 & $56.0 \%$ & $44.0 \%$ & \\
\hline No benefits received & 5 & $80.0 \%$ & $20.0 \%$ & 0.318 \\
\hline Income support received & 11 & $36.4 \%$ & $63.6 \%$ & \\
\hline No income support & 19 & $73.7 \%$ & $26.3 \%$ & 0.052 \\
\hline Council tax rebate received & 9 & $33.3 \%$ & $66.7 \%$ & \\
\hline No council tax rebate & 21 & $71.4 \%$ & $28.6 \%$ & 0.062 \\
\hline Milk tokens received & 5 & $20.0 \%$ & $80.0 \%$ & \\
\hline No milk tokens & 25 & $68.0 \%$ & $32.0 \%$ & 0.068 \\
\hline Housing benefit received & 10 & $40.0 \%$ & $60.0 \%$ & \\
\hline No housing benefit & 20 & $70.0 \%$ & $30.0 \%$ & 0.118 \\
\hline Amount spent on food/person/week (£) & 30 & $17.65 \pm 8.09$ & $14.95 \pm 6.37$ & 0.172 \\
\hline \multicolumn{5}{|l|}{ Housing } \\
\hline Rented housing & 22 & $54.5 \%$ & $45.5 \%$ & \\
\hline Bed and breakfast & 2 & $100 \%$ & - & 0.330 \\
\hline Rent paid in full by council & 11 & $45.5 \%$ & $54.5 \%$ & \\
\hline Household pays some or all rent & 13 & $69.2 \%$ & $30.8 \%$ & 0.223 \\
\hline Perceived adequacy of six basic household items & 30 & $2.9 \pm 0.5$ & $2.7 \pm 0.8$ & 0.147 \\
\hline \multicolumn{5}{|l|}{ Caregiver feels happy with family's diet } \\
\hline Yes & 10 & $30.0 \%$ & $70.0 \%$ & \\
\hline No & 13 & $69.2 \%$ & $30.0 \%$ & 0.074 \\
\hline
\end{tabular}

*One-tailed Student's t-test, Pearson's chi-squared test or Fisher's exact test as appropriate.

more recently than families without child hunger. Similar rates of child hunger were observed among the families who were in their first UK home and those who had moved.

\section{Immigration status}

Prevalence of child hunger did not differ by whether an immigration decision had been reached, and was similar among those families appealing against a negative decision and those granted status to remain.

\section{Caregiver characteristics and social support}

Mothers of children with hunger were on average 3 years younger than those of children without hunger. Families with and without child hunger did not differ in level of education or self-efficacy score of mothers, size or composition of household, child/caregiver ratio, lone care giving, presence of father, or indicators of social support from family and friends.

\section{Benefits}

Child hunger was more prevalent among the few families receiving no benefits, although the difference was not statistically significant. Child hunger was less prevalent $(0.052<P<0.118)$ among recipients of housing benefit, income support, a council tax rebate or milk tokens. There was no significant difference in the amount spent on food between households with and without child hunger. 
Table 5 Availability and perceived adequacy of food preparation facilities

\begin{tabular}{lcccr}
\hline Facility & \% without & $\begin{array}{c}\text { Adequacy } \\
\text { score }^{*}\end{array}$ & SD & $P$-value† \\
\hline Hot water & 0 & 3.04 & 0.69 & $<0.001$ \\
Kitchen & 3 & 2.86 & 0.59 & 0.014 \\
Cooker & 3 & 2.81 & 0.74 & 0.248 \\
Refrigerator & 3 & 2.81 & 0.79 & 0.021 \\
Cooking vessels & 3 & 2.88 & 0.52 & 0.003 \\
Dishes & 7 & 3.00 & 0.49 & 0.003
\end{tabular}

SD - standard deviation.

*Four-point scale: 1 = 'very bad'; 2 = 'bad'; 3 = 'good'; 4 = 'very good'. †Binomial test of likelihood of expressing a positive opinion.

\section{Housing conditions}

Both households in bed and breakfast accommodation were food-insecure at all levels. Child hunger was not significantly reduced by council payment of full rent (Table 4). Almost all families had access to basic facilities such as a kitchen, hot water, a cooker, cooking vessels and serving dishes and a refrigerator (Table 5). A majority had space for storing food (80\%) and a freezer (60\%), but lacked non-basic cooking items such as microwave ovens and toasters (70\%), When present, basic facilities were more likely to be described as adequate ('good' or 'very good') than as inadequate ('bad' or 'very bad'). However, responses varied widely, and mean perceived adequacy of the six basic household items took a value less than 3 ('good') for four households (13\%). There was a tendency among caregivers in households with child hunger to perceive their food preparation facilities as more adequate (Table 4).

\section{Discussion}

Although barriers to good nutritional practice are commonly observed for pre-school-aged refugee children in other Western countries ${ }^{22-25}$, we know of no other study of food insecurity among UK refugees with which to compare these results. Notwithstanding a number of limitations on study design, the results suggest that refugee families are highly vulnerable to food insecurity within the first two years of arrival in the UK. However, marginally significant associations between lack of benefits and child hunger even in this small and relatively well served sample suggest that receipt of certain benefits protects against child hunger. In contrast, levels of social support from family members did not appear to influence the risk of child hunger. Despite appreciable variation in maternal status and educational level, there was no indication that having a single or less educated mother was a significant risk factor for child hunger.

The study was designed as a pilot test of the survey methodology, and questions arise about appropriateness of the assessment methods, sampling, power and timing. The Radimer/Cornell food insecurity scale was originally developed in the USA, using the perspective of rural women to understand better the impact of relative hunger on physical and mental well-being. It examines issues around food insecurity using both a broad and a narrow conceptualisation of hunger ${ }^{19}$. It is a valid and reliable instrument for obtaining direct measures of perceived hunger in a number of settings ${ }^{26-30}$. Our results indicate that the concept and scale are valid among London's refugee communities because the progression of food insecurity is in the expected direction and fewer caregivers in households with child hunger were satisfied with the family diet (Table 4).

The prevalence estimates may not be representative of refugees in general because, by design, all families recruited were already in contact with outreach organisations and therefore well networked within the community. This potential selection bias more likely resulted in under-sampling of families with little contact with service providers and facing more challenges to maintaining a healthy diet than in over-sampling of families at greatest risk. Focus feedback discussions with local experts revealed strong concerns that a non-service based survey would reveal more food-insecure refugee families with young children. Although the sample size is inadequate to allow stringent statistical tests of hypotheses about the underlying causes and correlates of food insecurity, evidence that being a recent arrival, a younger mother and having lack of access to benefits are risk factors for child hunger corroborates qualitative statements by service providers working directly with refugee families ${ }^{14}$, and is cause for concern.

Mothers reported few changes in their situation during a feedback focus discussion conducted 4-8 weeks after interview, suggesting that food insecurity was persistent over time. However, the study was undertaken before the enforcement of the Immigration and Asylum Act (2000), under which the majority of support is now provided under a voucher scheme ${ }^{8}$. During data collection, rights to benefits were linked to immigration status through the provisions of The Children's Act of 1948 and asylum seekers with children were entitled to $70 \%$ of Income Support (£36.54 $+£ 18.62$ per child/week) while awaiting a decision. Housing was directly related to benefits and was mainly provided by the council. The impact on refugee diets of recent legislative changes such as the introduction of food vouchers and the policy of dispersal of refugee families to provincial towns warrants immediate evaluation.

The case for an increased public health focus on young child nutrition in refugee families in Britain appears strong. Promotion of healthy nutrition is one strategy to meet the challenge of delivering health to refugees ${ }^{10}$, and to contain future costs associated with poor long-term health outcomes among currently food-insecure refugees who remain ${ }^{7}$. Further research is needed to identify vulnerable groups, and design and target interventions. Future research should aim directly at testing whether the 
diets of young refugee children are of poor quality (inappropriate breast-feeding practices, low diversity of weaning foods, low consumption of meat and vegetables, high consumption of foods high in fat and sugar) and whether the dimensions of poor diet are related to low income, lack of transport to shops, information constraints (knowledge of cheap and healthy food sources, lack of basic nutrition and culinary knowledge) or lack of social support. Comparison of the relative impact on child hunger of different levels of cash benefits and food vouchers would be timely ${ }^{8}$.

\section{Conclusions}

Several conclusions have implications for further research and policy development. First, recently arrived refugee families with young children constitute a hard-to-sample population, but collection of detailed nutritional, economic and demographic data is feasible using an anthropological approach to study design and recruitment. Second, food insecurity and child hunger appear highly prevalent, and an expanded nutritional assessment of this socially excluded, under-served, poorly understood and rapidly growing population group is warranted. Third, social coping mechanisms appear ineffective in reducing the risk of child hunger. Fourth, evidence that families are most at risk of food insecurity shortly after arrival and that receipt of benefits protects against child hunger suggests that faster provision of more benefits to new arrivals may reduce the prevalence of child hunger. Last, policies for distribution of food vouchers and refugee resettlement should be developed with consideration of a number of potential threats to the nutritional status of young refugee children.

\section{Acknowledgements}

We thank the participants, the London Borough of Newham (Asylum Team Health Screening Service, Health Advocacy Team, Refugee Education Team and Community Renewal Programme), Hacia el Camino and two anonymous reviewers. Maria Baumbast, Vera Beining, Aratxu Blanco, Santhi Corcoran, Elisabeth Corey, Moya Hamilton, Jill Healey, Kalix Kalialia, Yanett Lara, Saida Munye, Luljeta Nuzi and Dahir Sheik assisted and advised. The King's Fund, Emory University Research Committee, and Halle Institute for Global Learning provided financial support.

\section{References}

1 Acheson D. Independent Inquiry into Inequalities in Health Report. London: The Stationery Office, 1998.

2 Coker J. A Report on the Health Education Authority's Expert Working Group on Refugee Health, Its Present State and Future Directions. London: Health Education Authority, 1998.
3 Kempson E, Bryson A et al., eds. Poverty and Food in Welfare Societies. Berlin: Edition Sigma, Die Deutsche Bibliothek, 1994.

4 Wilkinson RG. Equity, social cohesion and health. In: Strickland S, Shetty P, eds. Human Biology and Social Inequality. Cambridge: Cambridge University Press, 1998; $58-75$.

5 Kerr G, Lee E, Lorimor R, Mueller W, Lam M. Height distributions of US children: associations with race, poverty status and parental size. Growth 1982; 46: 135-49.

6 Karmi G. Refugee health - requires a comprehensive strategy. Br. Med.J. 1999; 305: 205-6.

7 Sellen DW, Tedstone A. Assessing food security and nutritional well being of preschool refugee children in the United Kingdom. In: Kershen AJ, Penn A, eds. Food in the Migrant Experience. London: Routledge, 2002; 214-28.

8 Home Office. Fairer, Faster, and Firmer - A Modern Approach to Immigration and Asylum. London: Stationery Office, 1998.

9 The Refugee Council. Asylum Statistics 1987-1997. London: The Refugee Council, July 1998.

10 Aldous J, Bardsley M, Daniell R, Gair R, Jacobson B, Lowdell $\mathrm{C}$, et al. Refugee Health in London. Key Issues for Public Health. London: The Health of Londoners Project, 1999.

11 Levenson R, Coker N. Health of Refugees: A Guide for General Practitioners. London: British Refugee Council, July 1999.

12 Hargreaves S, Bardsley M, Barker M, Kenny D, Morgan D, Roberts I, et al. Child Health in London. The Health and Social Characteristics of London's Children. London: The Health of Londoners Project, 1999.

13 Van den Bosch C, Brecker N. East London's new arrivals. Securing effective health care in East London and The City. In: Health in the East End. Annual Public Health Report 1997-98. London: East London \& City Health Authority, 1997.

14 Sellen DW, Tedstone A. Nutritional needs of refugee children in the UK. J. Roy. Soc. Med. 2000; 93: 360-4.

15 Anderson SA. Core indicators of nutritional status for difficult-to-sample populations. J. Nutr. 1990; 120(Suppl.): 1559-60.

16 Office for Population Census \& Surveys. General Household Survey. London: HMSO, 1995.

17 Sellen DW, Tedstone A, Frize J. Research Development: Young Refugee Children's Diets and Family Coping Strategies. London: The Kings Fund, October 2000.

18 Radimer KL, Olson CM, Greene JC, Campbell CC, Habicht JP. Understanding hunger and developing indicators to assess it in women and children. J. Nutr. Educ. 1992; 24(1): $36 \mathrm{~S}-44 \mathrm{~S}$.

19 Kendall A, Olson CM, Frongillo EA. Relationship of hunger and food insecurity to food availability and consumption. J. Am. Diet. Assoc. 1996; 96(10): 1019-24.

20 Centres for Disease Control and Prevention (CDC). Epi-Info, Version 6.04. Atlanta, GA: CDC, 1991.

21 SPSS, Inc. SPSS Proprietary Software, Release 10.0. Chicago, IL: SPSS, Inc., 2000.

22 Hassan K, Sullivan KM, Yip R, Woodruff BA. Factors associated with anemia in refugee children. J. Nutr. 1997; 127(11): 2194-8.

23 Perez-Escamilla R, Himmelgreen D, Ferris A. Community Nutritional Problems among Latino Children in Hartford, Connecticut. Technical Report No. 1. Storrs and Hartford, CT: Connecticut Family Nutrition Program, 1997.

24 Tuttle CR, Dewey KG. Determinants of infant feeding choices among southeast Asian immigrants in northern California. J. Am. Diet. Assoc. 1994; 94(3): 282-6.

25 Kocturk TO, Mjones S. Consumption pattern of infant foods by Turkish immigrants. Scand. J. Primary Health Care 1986; 4(1): $13-8$. 
26 Kendall A, Olson CM, Frongillo EA Jr. Validation of the Radimer/Cornell measures of hunger and food insecurity. J. Nutr. 1995; 125(11): 2793-801.

27 Frongillo EA Jr, Rauschenbach BS, Olson CM, Kendall A, Colmenares AG. Questionnaire-based measures are valid for the identification of rural households with hunger and food insecurity. J. Nutr. 1997; 127(5): 699-705.
28 Frongillo EA Jr. Validation of measures of food insecurity and hunger. J. Nutr. 1999; 129(Suppl. 2): 506S-9S.

29 Studdert LJ, Frongillo EA, Valois P. Household food insecurity was prevalent in Java during Indonesia's economic crisis. J. Nutr. 2001; 131(10): 2685-91.

30 Cassano PA, Frongillo EA. Annotation: developing and validating new methods for assessing community interventions. Am. J. Public Health 1997; 87: 157-8. 